\title{
Characterization of graphene nanosheets obtained by a modified Hummer's method
}

\author{
Renata Hack ${ }^{1}$,Cláudia Hack Gumz Correia ${ }^{2}$, \\ Ricardo Antônio de Simone Zanon ${ }^{1}$, Sérgio Henrique Pezzin ${ }^{1}$
}

\author{
${ }^{1}$ Universidade do Estado de Santa Catarina, Centro de Ciências Tecnológicas, \\ Programa de Pós-Graduação em Ciências e Engenharia de Materiais, \\ PGCEM/CCT/UDESC, cep 89219-710, Joinville, SC. \\ e-mail: renata.hack@gmail.com \\ ${ }^{2}$ Universidade da Região de Joinville,Laboratório de Materiais, \\ UNIVILLE, cep 89219-710, Joinville, SC.
}

\section{RESUMO}

O Grafite natural é uma fonte barata e abundante para obter nanofolhas de grafeno. O método mais eficiente para a produção em grande escala é o método químico, que se baseia na oxidação de grafite natural. Este artigo relata a síntese e caracterização de grafeno obtido pelo método Hummers com algumas modificações. Os resultados indicam um elevado grau de oxidação do grafite, provando que o processo foi eficiente. As análises de microscopia eletrônica de varredura de emissão de campo (FEG), microscopia electrônica de transmissão (TEM), espectroscopia Raman, análise termogravimétrica (TGA) e difração de raios-X revelaram que o grafeno produzido apresentou características similares ao grafeno comercial.

Palavras-chave: Grafeno, nanofolhas de grafeno, método de Hummers modificado.

\section{ABSTRACT}

Natural graphite is an inexpensive and abundant source to obtain graphene nanosheets. The most efficient method for large-scale production is the chemical method, which is based on the oxidation of natural graphite. This paper reports the synthesis and characterization of graphene obtained by the Hummers method with some modifications. The results indicate a high degree of graphite oxidation, proving that the process was efficient. Analyses of field emission scanning electron microscopy (FEG), transmission electron microscopy (TEM), Raman spectroscopy, thermogravimetric analysis (TGA) and X-ray diffraction showed that the graphene produced presented characteristics similar to the commercial graphene.

Keywords: Graphene, nanosheets graphene, Hummers method modified.

\section{INTRODUCTION}

In recent decades, nanotechnology and development of new materials had a major highlight in science. Physical and chemical phenomena do not completely known yet, caused by the generation of a much larger surface area compared to the volume of the nanoparticles, could be verified at nanoscale [1]. This surface act as an interface for the charge transfer, but is also responsible for the strong tendency of nanoparticles to form agglomerates, caused by van der Waals interactions between particles [2,3]. Nevertheless, it is believed that these new materials are the next step in the evolution of engineering materials [4].

In this context, carbon nanostructures has been gaining ground in materials science and revealing various applications due to the diversity of its structural forms and peculiar properties [5]. Among the reinforcements for the production of nanocomposites are nanoparticles of carbon black, carbon nanotubes, fullerenes, nanofibers and graphene. Graphene is a monolayer of $\mathrm{sp}^{2}$ carbon atoms arranged in a two-dimensional network structure (2D) with a hexagonal geometry [6]. Since its first isolation by Geim and Novoselov in 2004, graphene has been the subject of much research $[6,7,8,9]$. The properties of graphene have aroused interest in the scientific community due to its excellent mechanical strength, with tensile strength 200 times greater than that of steel, thermal conductivity, and electrical conductivity [10]. Regarding the electrical properties, graphene presents ballistic conduction and the mean free path of the charge carriers can reach a few micrometers, thereby leaving the mobility of carriers (electrons and holes) very high and becoming a great candidate to replace silicon in the electronics industry [11]. 
Currently, graphene is obtained by several different processes, but most of these production methods results in small amounts of the material. Among these processes are the chemical routes, such as the Hummer's method, considered the most promising for the production of graphene on a large scale. In this process, natural graphite $(\mathrm{NG})$ is oxidized by a mixture of acids and oxidizing agents, promoting the oxidation of graphite to graphite oxide (GO), containing oxygenated functional groups. Subsequently, the GO undergoes a thermal expansion and is then converted to graphene by reducing agents $[12,13]$.

In this paper, a modified Hummer's method was adopted for the production of graphene nanoparticles, in order to scale the process. This method was chosen due to two major factors: the possibility of obtaining high amounts of graphene, and low-cost equipment and reagents. The objective was to produce nanosheets of graphene from GO and characterize their morphology and thermal properties, comparing them with those of a commercial graphene, for further application in multifunctional nanocomposites.

\section{MATERIALS AND METHODS}

For this work we used two types of graphene, the first (G1) was obtained by oxidation and reduction of graphite, described in the next sessions, while the second (G2) commercially acquired.

\subsection{Graphite Oxide (GO)}

The graphite oxide (GO) was produced from natural graphite, using the method of Hummer [14]. This method has been slightly modified in relation to the process times and proportions of reagents. In a $500 \mathrm{ml}$ ound bottom flask it was added $1 \mathrm{~g}$ of natural graphite, $62.1 \mathrm{~g}$ of $\mathrm{H}_{2} \mathrm{SO}_{4}$ and $0.75 \mathrm{~g}$ of $\mathrm{NaNO}_{3}$. The mixture was kept in a water bath at approximately $6{ }^{\circ} \mathrm{C}$ under mechanical stirring at $180 \mathrm{rpm}$. After $15 \mathrm{~min}, 4,5 \mathrm{~g}$ of $\mathrm{KMnO}_{4}$ was slowly added to the mixture, always keeping the temperature below $20{ }^{\circ} \mathrm{C}$. After 30 min the system was allowed to reach the room temperature, and then left under stirring for $24 \mathrm{~h}$. After this period, a brown colored viscous liquid was obtained. To this mixture it was added $100 \mathrm{ml}$ of a $5 \%$ (w/w) $\mathrm{H}_{2} \mathrm{SO}_{4}$ solution, which causes an increase in temperature and changes the color to dark yellow. After $30 \mathrm{~min}, 280 \mathrm{ml}$ of a solution of $\mathrm{H}_{2} \mathrm{O}_{2}(3 \% \mathrm{w} / \mathrm{w})$ was added to the mixture. In this step of the process, a slight effervescence occurred when adding $\mathrm{H}_{2} \mathrm{O}_{2}$ solution and the color changed to bright yellow. The mixture was kept under stirring for $45 \mathrm{~min}$. The obtained mixture was filtered with the aid of a vacuum system comprising a Büchner funnel $12,5 \mathrm{~mm}$ diameter and filter paper with permeability of $26 \mathrm{~L} / \mathrm{s} . \mathrm{m}$. The material obtained in the filter paper was washed with $300 \mathrm{~mL}$ of a warm solution of $\mathrm{HCl} 10 \% \mathrm{w} / \mathrm{w}$ to remove metal ions remaining on the collected material. After drying the material over a period of $24 \mathrm{~h}$ at $60^{\circ} \mathrm{C}$, the material was suspended in $1 \mathrm{~L}$ of deionized water and vacuum filtered again. The washing process was repeated three times. The material was then dried in an oven for $24 \mathrm{~h}$ at a temperature of $60{ }^{\circ} \mathrm{C}$, yielding $\mathrm{GO}$.

\subsection{Expanded graphite oxide (OGE)}

A preheated muffle furnace at a temperature of $350{ }^{\circ} \mathrm{C}$ was used to expand the GO. The GO was distributed at the bottom of a $50 \mathrm{~mL}$ Erlenmeyer with an aluminum foil lid with small holes and taken to the furnace. After approximately 15 seconds the material has undergone expansion to give expanded graphite oxide (EGO).

\subsection{Reduced graphite oxide (G1)}

For the chemical reduction of EGO it was used a $4 \%$ (w/w) solution of sodium borohydride $\left(\mathrm{NaBH}_{4}\right)$ as reducing agent, as suggested by Si \& Samulki [15]. Studies performed by Shen et al [16] showed that the $\mathrm{NaBH}_{4}$ has same efficiency as hydrazine $\left(\mathrm{N}_{2} \mathrm{H}_{4}\right)$. In a $100 \mathrm{ml}$ beaker, $75 \mathrm{mg}$ of EGO were suspended in $75 \mathrm{~g}$ of deionized water and kept for $1 \mathrm{~h}$ in an ultrasound bath (Unique, USC-1800). Then, $15 \mathrm{~mL}$ of a solution of $\mathrm{NaBH}_{4}(95.0 \%) 4 \%$ w/w was added to the suspension. The $\mathrm{pH}$ of the suspension was adjusted between 9-10 with sodium carbonate solution at $4 \% \mathrm{w} / \mathrm{w}$. After $\mathrm{pH}$ adjustment, the suspension was maintained for $1 \mathrm{~h}$ at 80 ${ }^{\circ} \mathrm{C}$ under constant magnetic stirring. Then, the material was filtered with the aid of a vacuum system in a Büchner funnel of $12,5 \mathrm{~mm}$ diameter and filter paper with permeability of $26 \mathrm{~L} / \mathrm{s} . \mathrm{m}^{2}$. The material that remained on the filter paper was collected and washed with $250 \mathrm{~mL}$ of deionized water. After this process, the material was dried in a vacuum oven for $24 \mathrm{~h}$ at $60^{\circ} \mathrm{C}$, yielding produced graphene $(\mathrm{G} 1)$.

\subsection{Characterization}

Transmission electron microscopy was carried out in a Jeol JEM-2100 equipment. For the analyses, samples of the nanoparticles were dispersed in chloroform and then dripped onto the equipment support grid. The 
analyses of field emission scanning electron microscopy (FEG) were performed in a Jeol JSM-67017F equipment.

The Raman spectra were recorded in a WITEC UHTS300 spectrometer using a $597.990 \mathrm{~nm}$ laser.

Thermogravimetric analyses (TGA) were performed on an TGA Q50 V20.10 (TA Instruments, USA) equipment. Samples (approximately $10 \mathrm{mg}$ ) were subjected to heating from ambient temperature (approximately $24{ }^{\circ} \mathrm{C}$ ) to $550{ }^{\circ} \mathrm{C}$ at a heating rate of $10{ }^{\circ} \mathrm{C} / \mathrm{min}$, under an inert atmosphere with $\mathrm{N}_{2}$ flow of 50 $\mathrm{ml} / \mathrm{min}$.

X-ray diffraction analyses were done in a Shimadzu XRD-6000 equipment operating at $40.0 \mathrm{kV}$ and $30.0 \mathrm{~mA}$, with a wavelength of $1.54060 \AA$. The measurements were made at room temperature, with $2 \theta$ varying from $10^{\circ}$ to $60^{\circ}$.

\section{RESULTS AND DISCUSSION}

\subsection{Field emission scanning electron microscopy (FEG)}

Figure 1 (a-b) show the images of natural graphite and GO, respectively. It is possible to verify that the graphite structure is formed by several thick layers arranged in stacks. Moreover, the oxidation of graphite caused changes in its morphology, with a wrinkled appearance with several folds. This wrinkled aspect can be explained by the oxidation process to promote the admission of hydroxyl and epoxy functional groups, altering the hybridization of $\mathrm{sp}^{2}$ carbons (planar structure) to $\mathrm{sp}^{3}$ (tetrahedral structure).

One can also observe that the GO is formed by a layered structure. This is due to the oxidation of the material, since the greater the degree of oxidation, the higher are the spaces between the functionalized layers. Dikin et al (2007) gave results similar to that observed obtaining a layered structure with several folding [17].
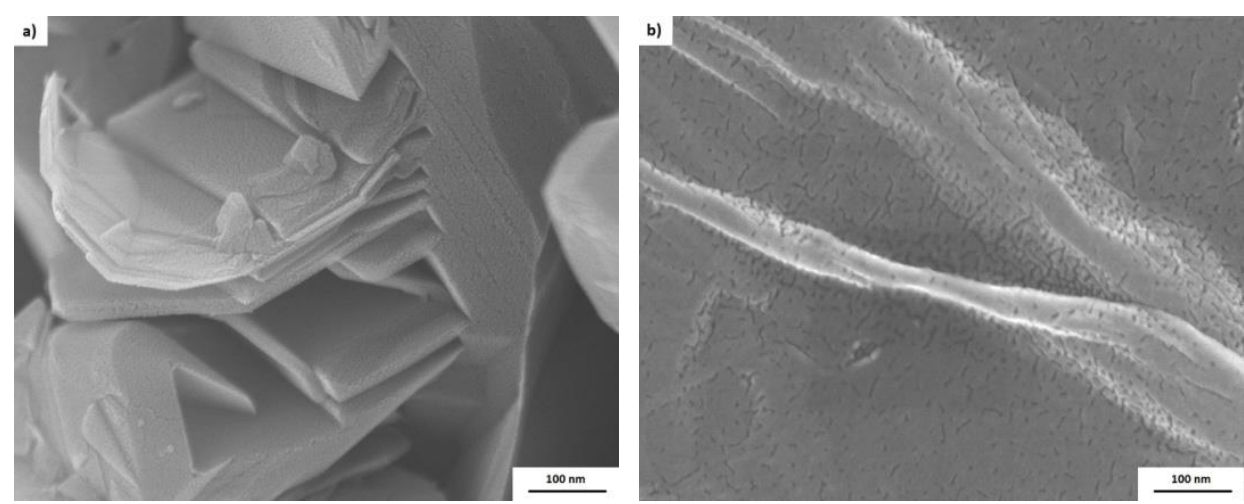

Figure 1: FEG images of (a) natural graphite and (b) GO.

Figure 2 (a) shows the morphology of EGO nanoparticles. It is observed that the EGO underwent expansion and altered the morphology of the material, exposing a structure full of voids. Yasmim et al (2006) found similar results, reporting that after its expansion, the graphite showed a structure with layers detached from each other [18]. Looking at Figure 2 (b) it is possible to observe that the sample has still some folds and crevices, as shown in Figure 1 (b). The chemical reduction of GO causes partial removal of functional groups that are still present after expansion. However, this does not completely restore the graphitic structure of the material, namely, chemical reduction of the GO does not recover crystal defects caused by oxidation, so it is still possible to observe a wrinkled morphology of the material. In Figure 2 (b), it is possible to observe the presence of well-dispersed layers, indicating that, after the chemical reduction, the material is not arranged in the initial graphitic crystalline structure. 

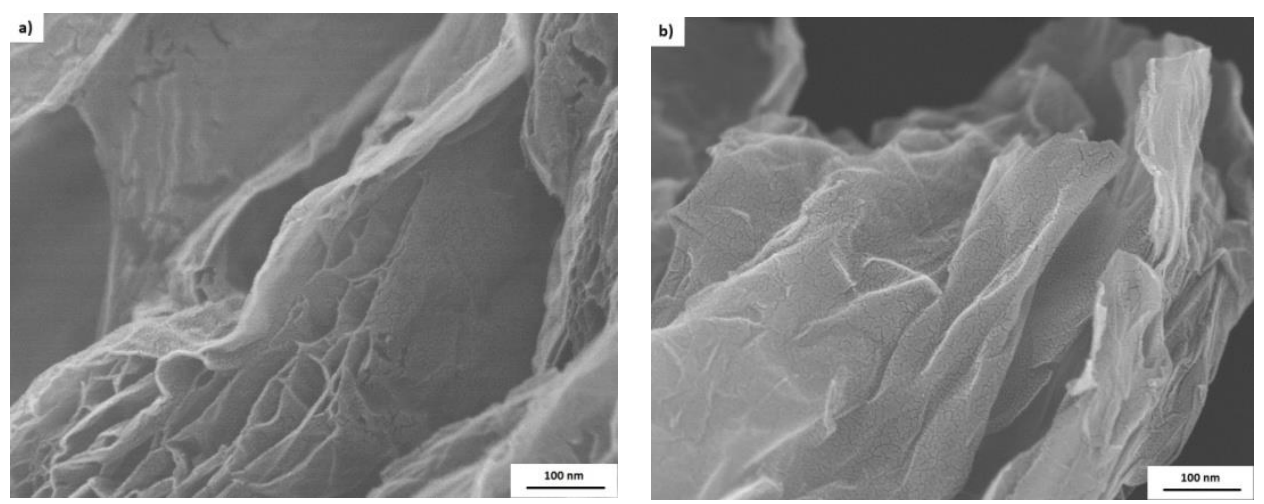

Figure 2: FEG images of (a) EGO and (b) G1.

It is also observed, by the FEG micrographs, that the nanoparticles went from an ordered lamellar arrangement (natural graphite) to an asymmetric structure, with different sizes and a rough and discontinuous layered morphology (G1). This fact is related to the oxidation/expansion processes and, possibly, also to the sonication procedure, as the passage of ultrasound waves through the material dispersed in a liquid medium leads to the formation of bubbles, suffering collapse when their volume is increased, and releasing large amounts of energy that can shatter the structure of material [19]. The rough morphology of G1 sheets was also observed in other studies using ultrasound to the dispersion of graphite in the solvent, also indicating the formation of structures with different shapes and sizes [20].

Figure 3 presents a G2 FEG image, showing a layered flat morphology of the sample surface, similar to the G1 structure in Figure 2 (b).

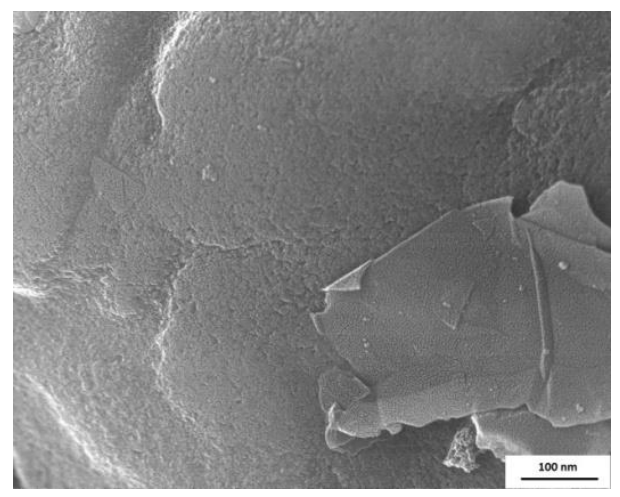

Figure 3: FEG image of G2.

Nevertheless, as commented by Kim et al (2010) [21], methods from the graphite oxide to obtain graphene have a relatively good yield, but in general, lead to the formation of irregular and defects structures, when compared to bottom-up methods, which are based on the formation of graphene from gases with a high carbon concentration.

\subsection{Transmission electron microscopy (TEM)}

Figure 4 (a and b) refers to the GO images taken by transmission electron microscopy. It was observed that the material has a good level of translucency, indicating a high degree of oxidation. It can be also seen in Figure 4 that the GO sheet presents some darker regions, which are related to the stacking of some GO layers, as observed by other researchers [22]. 

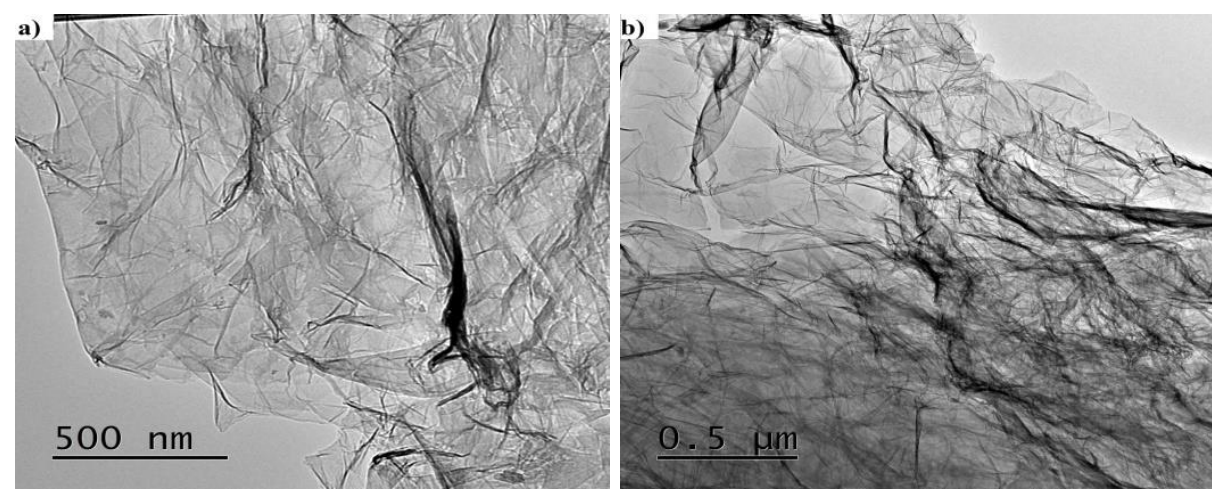

Figure 4: TEM images of GO: (a) Scale bar $500 \mathrm{~nm}$; (b) Scale bar $0.5 \mu \mathrm{m}$.

TEM micrograph (Figure 5a) and electron diffraction pattern (Figure 5b) of EGO show that the level of exfoliation by thermal expansion at $350{ }^{\circ} \mathrm{C}$ was high due to the translucency of platelets, indicating that there are few layers of bundled sheets. Kim et al (2009b) [22] also observed similar results, as well as Grayfer et al (2011) [23], expanding graphite oxide at a temperature of $900{ }^{\circ} \mathrm{C}$. This similarity indicates that the exfoliation of graphite oxide can be accomplished even at much lower temperatures, such as $350{ }^{\circ} \mathrm{C}$. The electron diffraction pattern obtained from the sample, Figure 5 (b) shows a well-defined hexagonal array, indicating that the analyzed material does not have a significant number of superimposed sheets.
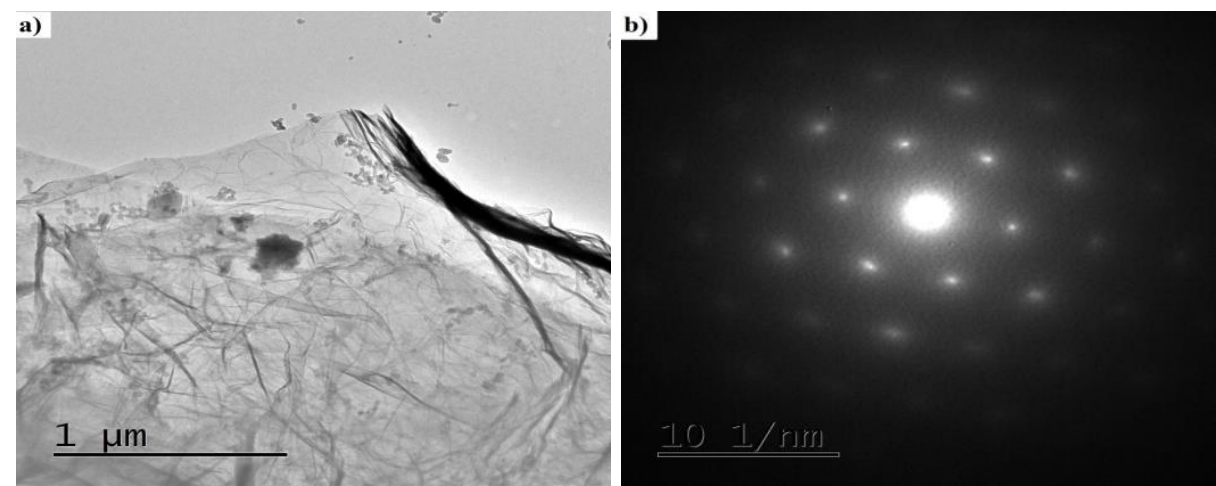

Figure 5: (a) TEM image and (b) electron diffraction pattern of a EGO sample.

A similar morphology, consisted of bundled sheets, is also observed for G1 samples (Figure 6a). Looking at the electron diffraction pattern for G1 (Figure 6b), it can be observed the presence of internal points with lower light intensities than other external points, evidencing a polycrystalline material. In any case, it can be said that the material has a hexagonal pattern and a structure containing a smaller number of layers than the original natural graphite.

The TEM characterization of the commercial graphene sample, G2, is presented in Figure 6 (c and d). Although TEM images are similar for the G1 produced in this work and the commercial graphene, Figures 6 (a) and 6 (c), some marked differences are noted in the electron diffraction patterns, Figures 6 (b) and 6 (d). For the G2 sample, the internal points are more intense than the external points, characterizing the presence of graphene monolayers [24] and, thus, indicating that the commercial graphene had a higher number of exfoliated structures than graphene $(\mathrm{G} 1)$ produced in this work. 

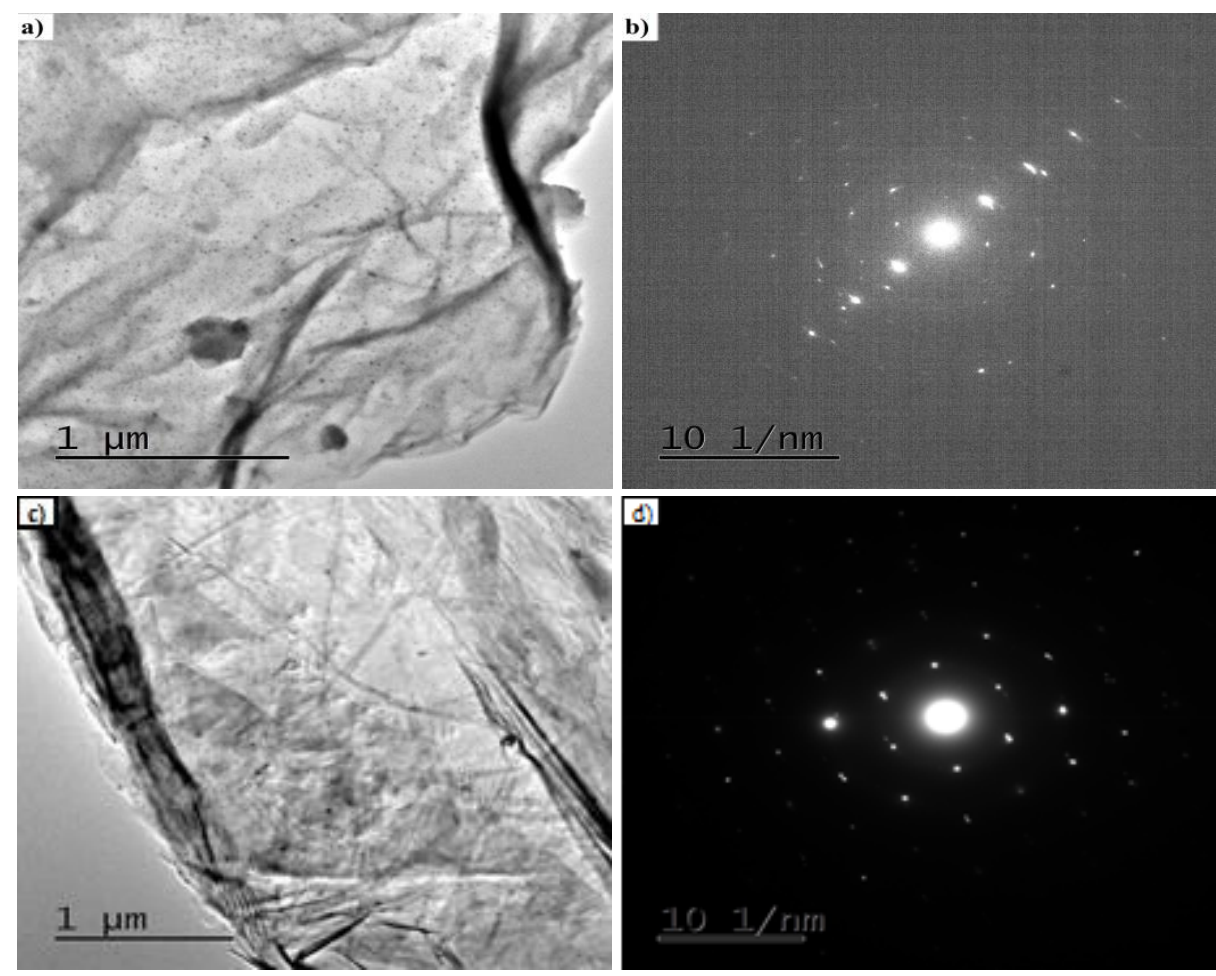

Figure 6: TEM image and (b) electron diffraction pattern of a G1 sample.

\subsection{Raman spectroscopy}

Raman spectroscopy is widely used in structural and electronic characterization of graphitic materials. The Raman spectrum provides useful information on defects, carbon $\mathrm{sp}^{2}$ vibrations and the stacking order.

Figure 7 shows the Raman spectra for graphite, GO, EGO, G1 and G2. Figure 7 (a), for the G2 sample, shows a peak at $1583 \mathrm{~cm}^{-1}$ related to the $\mathrm{G}$ band of the graphitic structure ( $\mathrm{sp}^{2}$ carbon), also observed by Fim (2012) [25]. It is also possible to observe a broad peak located at $2712 \mathrm{~cm}^{-1}$ corresponding to the 2D band.

Analyzing the spectrum of Figure 7 (b) for natural graphite, it is also noted a band at $1573 \mathrm{~cm}^{-1}$ related to the $\mathrm{G}$ band of graphitic structure, and a wide and high peak located at $2708 \mathrm{~cm}^{-1}$ related to the $2 \mathrm{D}$ band, as reported by Ferrari (2007) [26].

Figure 7 (c) shows the Raman spectrum of a GO sample. It can be seen the D band located at 1348 $\mathrm{cm}^{-1}$ and a second peak located at $1587 \mathrm{~cm}^{-1}$, related to the $\mathrm{G}$ band of graphitic structure ( $\mathrm{sp}^{2}$ carbon). Gupta et al (2017) [27] also observed bands D and G in their study, characteristic of GO.

In Figure 7 (c) it is observed that these two peaks are not very intense and very wide, having very specific characteristics of amorphous carbon, with broad D and $\mathrm{G}$ bands and no peaks in the second order zone.

The Raman spectrum of EGO can be seen in Figure 7 (d). It is possible to verify a partial restoration of the carbon $\mathrm{sp}^{2}$ network, located at $1600 \mathrm{~cm}^{-1}$. In fact, it is noted the appearance of a peak in the second order zone, indicating that the material has organized graphene sheets. Fim (2012) [25] also observed this behavior in graphite oxide after heat treatment.

Figure 7 (e) shows the Raman spectrum of a G1 sample. It is observed three very obvious peaks. The first located in $1360 \mathrm{~cm}^{-1}$ corresponds to the $\mathrm{D}$ band, the second located in $1587 \mathrm{~cm}^{-1}$ is associated with the $G$ band. It is noted an attempt to restore the $\mathrm{sp}^{2}$-carbon network, also suggesting the appearance of arranged graphene sheets. 


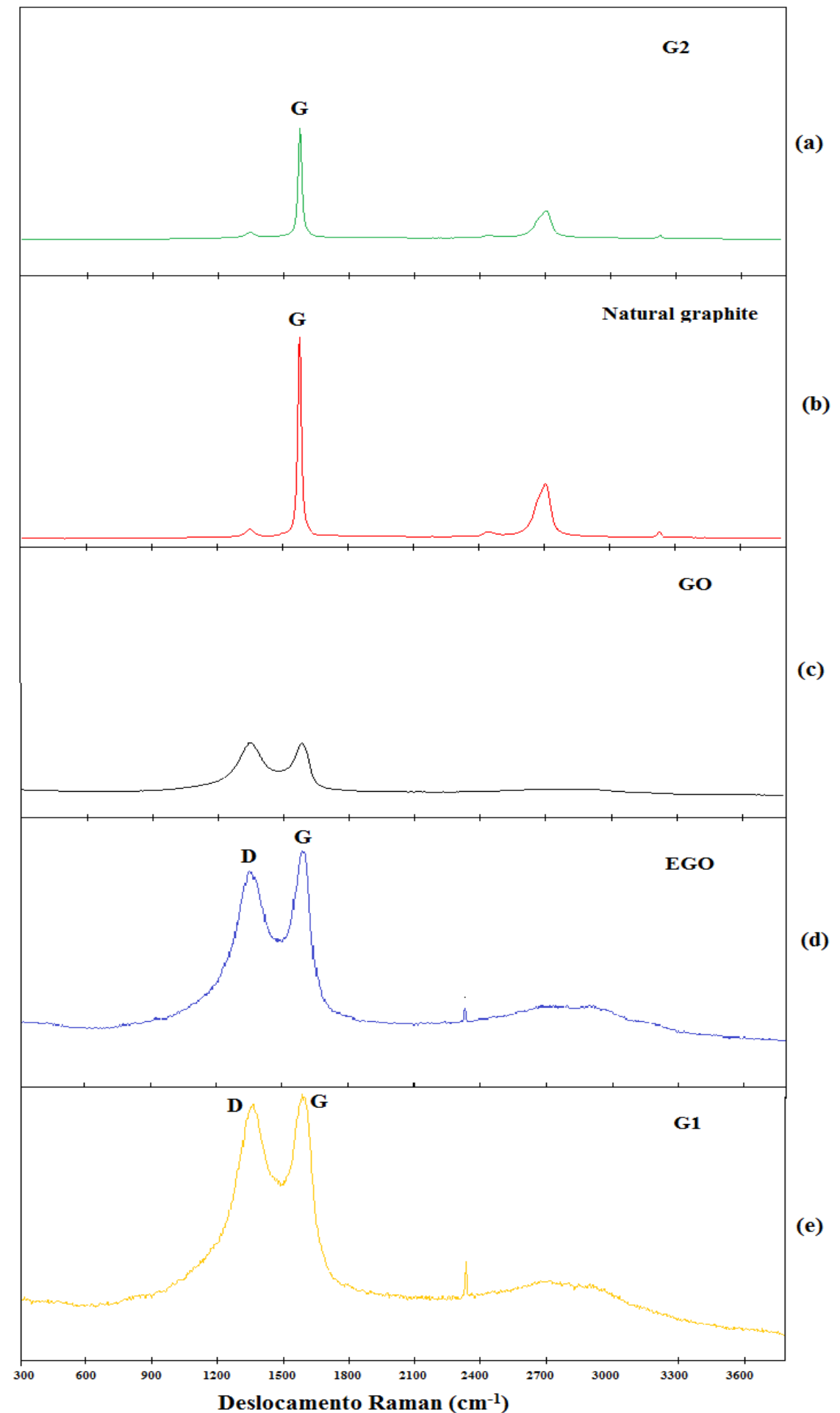

Figure 7: Raman Spectrum: (a) G2; (b) natural graphite; (c) GO; (d) EGO and (e) G1.

\subsection{Thermogravimetric Analysis (TGA)}

Figure 8 shows the mass loss curves for G2, G1, GO and EGO obtained by thermogravimetric analysis. Analyzing the curve for GO, there are observed two mass loss events. The first occurs at about $140{ }^{\circ} \mathrm{C}$, about 13 $\%$ of mass loss, and the second occurs at $320{ }^{\circ} \mathrm{C}$, corresponding to ca. $30 \%$ mass loss. Ali et al (2009) [28] obtained similar results by thermogravimetry, and has detected by mass spectrometry analysis (TGA-MS) that the loss of water and $\mathrm{CO}_{2}$ occurs simultaneously in the first mass loss event, while the second mass loss 
event may be related to the disruption of the carbon network [29]. Chen et al (2010c) [30] also found very similar results and attributed the first event to the removal of $\mathrm{O}_{2}, \mathrm{CO}, \mathrm{CO}_{2}$, and $\mathrm{H}_{2} \mathrm{O}$. The authors suggest that the second event is due to the reactivity of oxygen present in the GO structure, which takes oxygen present in the $\mathrm{GO}$ structure to react with the carbon surface to form $\mathrm{CO}$ and $\mathrm{CO}_{2}$.

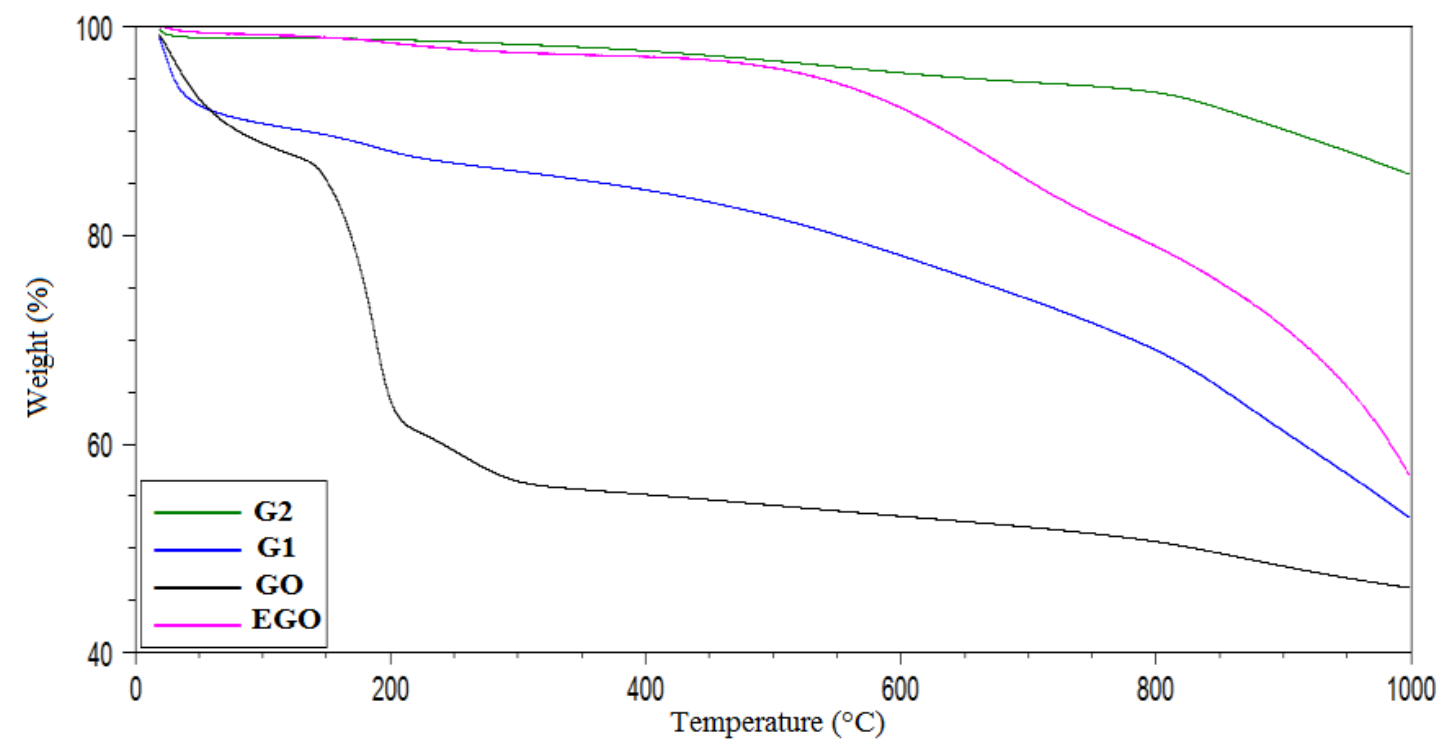

Figure 8: Mass loss versus temperature curves for samples G2, G1, OG and OGE.

The mass loss curve of EGO (pink curve), shows only one stage, a different behavior in comparison to that found for GO curve. The mass loss starts at about $550{ }^{\circ} \mathrm{C}$ and can be attributed to loss of oxygenated groups that may be present in the sample. Among $550{ }^{\circ} \mathrm{C}$ to $1000{ }^{\circ} \mathrm{C}$ this behavior may be associated with structural rearrangement of carbon.

The weight loss curve for the G2 sample also shows only a degradation stage, indicating that there is a lack of oxygen and hydroxyl groups in G2 [30], and suggesting a high degree of reduction and quality in the manufacturing process.

The mass loss curve of G1 is similar to that of G2, with only one stage of degradation, also indicating the absence of oxygen and hydroxyl groups, and, thus, suggesting a successful reduction process. It can be also seen in the curve for the G1 sample, an initial mass loss at $95{ }^{\circ} \mathrm{C}$, which is associated with the sample's moisture content. Furthermore, all analyzed samples presented a high amount of residue, over 50\%, at 1000 ${ }^{\circ} \mathrm{C}$. Stankovich and coworkers [31] showed that after the reduction, i.e., after removal of the oxygenated groups, the thermal stability of the material increases, thus explaining the high content of residue, as observed in this study. Nevertheless, the variation of the residue amount when comparing G1 and G2, ca 50\% and $85 \%$, respectively can be related to some GO remaining in G1.

\subsection{X-Ray Diffraction (XRD)}

$\mathrm{X}$-ray diffraction (XRD) analyses were carried out to assess the effectiveness of the oxidation, expansion and reduction of graphite. Figure 9 (a) illustrates the XRD pattern for the natural graphite, GO, EGO, G1 and G2. The diffractogram for natural graphite shows the presence of a high intensity peak at $2 \theta=26,65^{\circ}$, which corresponds to a basal spacing of $0.334 \mathrm{~nm}$, followed by a peak at $54,92^{\circ}$, both of them characteristics of graphite [32,33].

Analyzing the XRD pattern of the GO sample, it can be seen that after oxidation the peaks related to the natural graphite planes almost disappears; it is only possible to observe a very low intensity halo. 


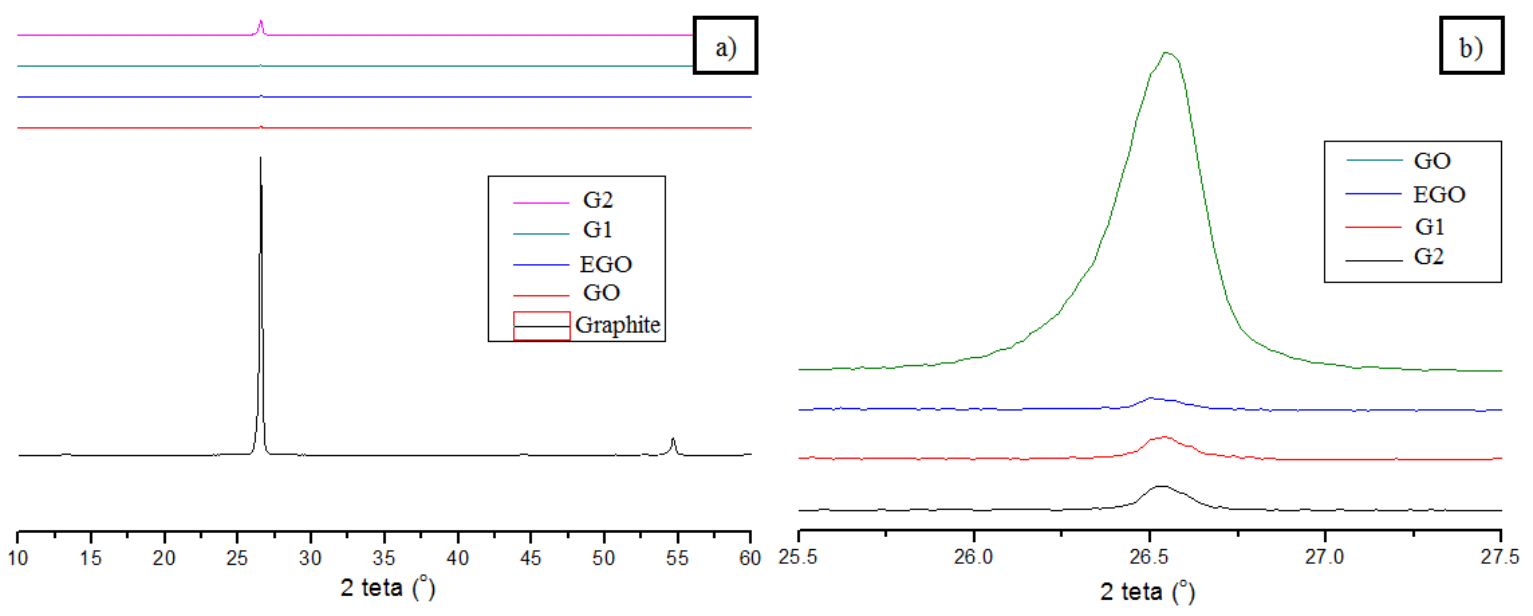

Figure 9: XRD diffraction patterns of natural graphite, GO, EGO, RGO (G1) and G2 samples.

Figure 9 (b) shows in more detail the low intensity region of Figure 9 (a). The XRD patterns of GO and EGO confirms the intercalation and further exfoliation of most of the graphite layers.

In the diffractogram of the G1 sample, it is observed only a low intensity halo, even less intense than those observed for GO and EGO. This suggests that the chemical reduction of expanded graphite oxide, although changes its hybridization from $\mathrm{sp}^{3}$ to $\mathrm{sp}^{2}$ and eliminates functional groups that have been introduced in the oxidizing material, does not restore the graphite lamellar structure.

The diffractogram related to the G2 sample shows a higher intensity peak at $26.5^{\circ}$, indicating the formation of graphene nanoplatelets with the same basal spacing as natural graphite.

\section{CONCLUSION}

Graphene nanoplatelets have been successfully prepared by graphite oxidation followed by thermal expansion of the graphite oxide and further reduction with sodium borohydride.

Regarding the thermal expansion of graphite oxide, it was proved that the exfoliation takes place at a $350{ }^{\circ} \mathrm{C}$, a much lower temperature than most of the procedures reported in the literature. Moreover, the reduction of the expanded graphite oxide by sodium borohydride proved to be very effective.

\section{BIBLIOGRAFIA}

[1] PEZZIN, S.H., AMICO, S.C., COELHO, L.A.F., "Nanoreinforcements for nanocomposite materials", In: BERGMANN, C.P., ANDRADE, M.J., Nanostructured Materials of Engineering Applications, 1 ed., Editor Springer Berlin Heidelberg, 2011.

[2] FIEDLER, B., GOJNY, F.H., WICHMANN, M.H.G., et al., "Fundamental aspects of nano-reinforced composites", Composites Science and Technology", v 66, n.16, pp 3115-3125, Dec. 2006.

[3] GOUMRI, M., POILÂNE, C., RUTERANA, P., et al., "Synthesis and characterization of nanocomposites films with graphene oxide and reduced graphene oxide nanosheets", Chinese Journal of Physics, v 55, n.2, pp 412-422, Apr. 2017.

[4] AMICO, S.C., PEZZIN, S.H., COELHO, L.A. F., "Nanocompósitos de matriz polimérica com nanotubos de carbono", In Pohlmann, A.R., Petter, C.O.; Balzaretti, N.M., et al, Tópicos em Nanociência e Nanotecnologia, 1 ed., Porto Alegre, Brazil, Editor of UFRGS, 2008.

[5] KHOLMANOV, I.N., CAVALIERE, E., CEPEK, C., et al., "Catalytic chemical vapor deposition of methane on graphite to produce graphene structures", Carbon, v 48, n. 48, pp 1619-1625, Apr. 2010.

[6] NOVOSELOV, K.S., GEIM, A.K., MOROZOV,S. V., et al., "Two-dimensional gas of massless Dirac fermions in graphene", Nature, v 438, pp 197-200, Nov. 2005.

[7] VILlAR-RODIL, S., PAREDES, J.I., MARTINEZ-ALONSO, A., et al., "Preparation of graphene dispersions and graphene-polymer composites in organic media", Journal of Materials Chemistry, v 19, pp 3591-3593, Apr. 2009.

[8] LIANG, J., WANG, Y., HUANG, Y., et al., "Electromagnetic interference shielding of graphene/epoxy 
composites”, Carbon, v 47, n. 3, pp 922-925, Mar. 2009.

[9] ZHANG, Y., TAN, Y., STORMER, H.L., et al., "Experimental observation of the quantum Hall effect and Berry`s phase in graphene”, Nature, v 438, pp 201-204, Nov. 2005.

[10] LEE, C., WEI, X.D., KYSAR, J.W., et al., "Measurement of the elastic properties and intrinsic strength of monolayer graphene", Science, v 321, n. 5887, pp 385-388, Jul. 2008.

[11] SCHOENENBERGER C., "Band structure of graphene and carbon nanotubes: Na exercise in condensed matter physics", University of Basel, Apr. 2000.

[12] COMPTON, O.C., NGUYEN, S.T., "Graphene oxide, highly reduced graphene oxide, and graphene: versatile building blocks for carbon-based materials", Small, v 6, n.6, pp 711-723, Mar. 2010.

[13] SILVA, D.D.S., SANTOS, W.F., PEZZIN, S.H., "Nanocompósitos de matriz polimérica produzidos a partir do grafite natural”, Matéria, v 18, n. 2, pp. 1260-1272, Mai. 2013.

[14] HUMMERS, W.S., OFFEMAN, R.E., "Preparation of graphitic oxide", Journal of the American

Chemical Society, v 80, n. 6, pp. 1339, 1958.

[15] SI, Y., SAMULSKI, E.T., "Synthesis of water soluble graphene”, Nano Letters, v 8, n. 6, pp 1679-1682, May. 2008.

[16] SHIN, H-J., KIM, K.K., BENAYAD, A., et al., "Efficient reduction of graphite oxide by sodium borohydride and its effect on electrical conductance", Advanced Functional Materials, v 19, n. 12, pp 1987-1992, Jun. 2009.

[17] DIKIN, D.A., STANKOVICH, S., ZIMNEY, E.J., et al., "Preparation and characterization of graphene oxide paper", Nature, v 448, pp 457-460, Jun. 2007.

[18] YASMIN, A., LUO, J-J., DANIEL, I.M., "Processing of expanded graphite reinforced polymer nanocomposites", Composites Science and Technology, v 66, n. 9, pp 1128-1189, Jul. 2006.

[19] CHEN, G., WENG, W., WU, D., et al, "Preparation and characterization of graphite nanosheets from ultrasonic powdering technique”, Carbon, v 42, n.4, pp 753-759, Dec. 2003.

[20] LOTYA, M., KING, P.J., KHAN, U., et al., "High-concentration, surfactant-stabilized graphene dispersions", ASC Nano, v 4, n.6, pp 3155-3162, May. 2010.

[21] KIM, H., ABDALA, A.A., MACOSKO, C.W., "Graphene/Polimer Nanocompositer”, Macromolecules, v 43, n. 16, pp 6515-6530, Jul. 2010.

[22] KIM, K-S., ZHAO, Y., JANG, H., et al., "Large-scale pattern growth of graphene films for stretchable transparent electrodes", Nature, v 457, pp 706-710, Jan. 2009.

[23] GRAYFER, E.D., NAZAROV, A. S., MAKOTCHENKO, V.G., et al., "Chemically modified graphene sheets by functionalization of highly exfoliated graphite", Journal of Materials Chemistry, v 21, n. 21, pp 3410-3414, Nov. 2010.

[24] HERNANDEZ, Y., NICOLOSI, V., LOTYA, M., et al., "High-yeld production of graphene by liquidphase exfoliation of graphite”. Nature nanotechnology, v 3, pp 563-568, Aug. 2008.

[25] FIM, F.C. Síntese de propriedades de nanocompósitos de polietileno/nanolâminas de grafeno obtidos através de polimerização in situ, D.Sc. Thesis, UFRGS, Porto Alegre, RS, Brazil, 2012.

[26] FERRARI, A.C., "Raman spectroscopy of graphene and graphite: Disorder, electron-phonon coupling, doping and nonadiabatic effects”, Solid State Commun, v 143, pp 47-57, Apr. 2007.

[27] GUPTA. V., SHARMA,N., SINGH, U., et al., "Higher oxidation level in graphene oxide”, Optik- International journal for light and electron optics, v. 143, pp. 115-124, Aug. 2017.

[28] ALI, F., AGARWAL, N., NAYAK, P.K., et al. "Chemical route to the formation of graphene", Current Science, v. 97, n. 5, pp 683-685, Sep. 2009.

[29] AKHAVAN, O. "The effect of heat treatment on formation of graphene thin films from graphene oxide nanosheets", Carbon, v 48, n. 2, pp, 509-519, Fer. 2010.

[30] CHEN, W., YAN, L., BANGAL, P.R., "Preparation of graphene by the rapid and mild thermal reduction of graphene oxide induced by microwaves", Carbon, v 48, n. 4, pp 1146-1152, Apr. 2010.

[31] STANKOVICH, S., DIKIN, D.A., DOMMETT, G.H.B., et al., "Graphene-based composite materials", Nature, v 442, pp 282-286, Jul. 2006.

[32] LI, Z. Q., LU, C.J., XIA, Z.P., et al., "X-ray diffraction patterns of graphite and turbostratic carbon", Carbon, v 45, n. 8, pp 1686-1695, Jul. 2007. 
[33] MCALLISTER, M.J., LI, J-L., ADAMSON, D.H., et al., "Single sheet functionalized graphene by oxidation and thermal expansion of graphite", Chemistry of Materials, v 19, n. 18, pp 4396-4404, May. 2007. 